1925-32, 36. The weight percentages caught in different months were :-April 14 per cent, May 37, June 18, August 2, September 2; which means that already in April sturgeon are present abundantly in the Vistula and that in August the migration is over. The heaviest individuals appear in April and May, and after June and July the weight suddenly falls, an indication that the latter are the spawning months, since the weight of roe makes up about 20 per cent of the total body weight. The actual spawning grounds in the Vistula have never been discovered.

Now the only area in which a close season is enforced is Pomerania, and there the close season runs from July 15 until August 31 ; so that during the very time when the river ought to be left undisturbed for spawning, fish are liable to be caught. The close season should be extended in area, and also in time to cover the spawning period, say from June 1 to the present closing date. Although destruction of sturgeon for food has had something to do with the growing scarcity of the species, it must not be forgotten that still more is its disappearance due to the pollution of the rivers by the refuse of industrial and human centres. (Wlodzimerz Kulmatycki, in Ochrona Przyrody, Warsaw, 12, 8 ; 1932.)

\section{The Spring Flush}

Pastures are now approaching the peak of their productivity in England and the skill of the grazier is shown in the most economical conversion of the plentiful growth of grass into a saleable form. The problem has always been recognised as a difficult one, namely, the adjustment of the balance between the interests of the pasture and the grazing stock. Writing of the utilisation of grazing land, Arthur Young says : "There are two opinions directly contrary to each other : first it is asserted by one set of graziers, that, let the grass to be fed consist of ever so many acres, that the cattle should have it all at once. Secondly the other set advance that large fields of fifty, eighty or an hundred acres should be divided, that the farmers may change his stock from one to another and give the grass fresh and fresh".

The difficulty of putting these rival theories to the test seemed insuperable to Arthur Young, on the ground of soil variation and individuality in the grazing stock. Only recently, more than a century after the above was written, are scientific methods of the evaluation of herbage by their botanical composition and the performance of grazing stock being worked out. The difficulties are still there, but modern technique in the field, and the treatment of the data by statistical methods, enables valid conclusions to be drawn from data which present the high degree of variability associated with living material. New aspects of the utilisation of grass land are continually coming to light, and no crop is at present so much in favour for scientific research.

The outstanding feeding value of young grass, the superior qualities of selected strains of the native grasses and clovers, and the extraordinary influence which the grazing animal can exert on the direction of development of a pasture, are all recently established points of first rate importance in grass land management. Pasture management can never be a rule of thumb operation but the time is rapidly approaching when graziers will have a body of wellestablished principles at their command, in place of the rival opinions no less tenaciously held now than in the time of early writers.

\section{Societies and Academies}

\section{LoNDON}

Physical Society, April 7. A. H. Blatchforn: The diffraction of $\mathrm{X}$-rays by liquid sulphur. The $\mathrm{X}$-ray diffraction effects given by liquid sulphur at various temperatures between $130^{\circ} \mathrm{C}$. and $260^{\circ} \mathrm{C}$. indicate an unstable grouping of atoms of sulphur which becomes less pronounced with increased tem. perature, and changes in form gradually up to $220^{\circ} \mathrm{C}$., when there is a sudden alteration corresponding to the change from the form $\mathrm{S}_{k}$ to $\mathrm{S}_{\mu}$. Raman and Ramanathan's theory of X-ray scattering by liquids is applicable to some extent at temperatures near the melting-point. E. Gwynne Jones : The hyperfine structure of perturbed series. Rules governing such effects are derived. It is found that these rules are not analogous to those obtained from the analysis of multiplet structures. A. J. BRADLEY and A. H. JAY : Quartz as a standard for accurate latticespacing measurements. A test has been made of the use of quartz as a standardising substance for very accurate lattice-spacing determinations. With copper$K_{a}$ radiation it gives a very good photograph with many sharp $K_{a}$ doublets, which may be measured with accuracy. A redetermination of the axial ratio from an $\mathrm{X}$-ray powder photograph gave $c / a=$ $1 \cdot 10002 \pm 0 \cdot 00004$, and this value was confirmed by X-ray measurements on several other crystals. Assuming Bergqvist's value for $d_{100} \quad(4246.02 \mathrm{X}$ units) it was found that $a=4902 \cdot 9 \mathrm{x} ., c=5393 \cdot 3 \mathrm{x}$. The values of $d_{100}$ at $18^{\circ} \mathrm{C}$. for different specimens all lay between $4245 \cdot 9_{5}$ and $4246 \cdot 3_{0}$. L. H. Mar'tiN and $K$. C. LANG: The thermal conductivity of water. The parallel-plate method was used over the range $7^{\circ}-60^{\circ} \mathrm{C}$., the apparatus being especially designed to cope with the difficulties which arise in the measurement of the conductivity of a volatile liquid. Two series of measurements were made, the plates in one apparatus having approximately three times the area of those in the other.

Society of Public Analysts, May 3. S. G. WiLlimotr : An investigation of solanine poisoning. In two districts of Cyprus there is a practice of eating potato shoots and leaves as vegetables, and last year an epidemic of poisoning was traced to this cause. The amount of solanine found in the green shoots of the Irish potato plants consumed in these cases was more than five times the quantity present in the tubers of the same plants. It was found that the solanine content of potato shoots diminishes as the altitude at which the plant is grown increases. Habitual consumers of potato shoots probably acquire immunity to the alkaloid. F. E. Humphreys and H. Phillips : Examination of leather for the presence of extractable chromium compounds. In view of the fact that cases of dermatitis have been attributed to the wearing of chrome-tanned leather, experiments have been made to ascertain the amounts of chromium compounds which can be extracted from various types of chrome leather, under conditions similar to those which the leather encounters during wear. Chrome leathers suspected of causing dermatitis did not contain a greater quantity of waterextractable chromium than did normal leather, but many chrome leathers might irritate the skin of a person particularly sensitive to chromium compounds. Solutions resembling sweat in composition do not remove much more chromium, either as chromate or 
trivalent chromium compounds, than does water, although slightly acid solutions tend to extract slightly larger amounts than neutral solutions. W. M. SeABER : Barium as a normal constituent of Brazil nuts. Barium occurs as a normal constituent of Brazil nuts, the amounts found in 14 samples of the shelled nut of different seasons ranging from 0.02 to 0.31 per cent. As a rule, Para nuts contain less than Manaos nuts. Nearly the whole of the barium is in an insoluble form, but a considerable proportion of it can be extracted by 0.15 per cent hydrochloric acid, and with higher concentrations of acid it is practically all dissolved. Herbert Hawley : The phytosteryl acetate test as a routine method for examining butter fats. A method is described in which the sterols are directly extracted from a small amount of butter fat by shaking with chloroform and an alcoholic solution of digitonin, and then converted into acetates the melting point of which is determined. The method will detect 5 per cent of vegetable fat in butter or ghee.

Royal Meteorological Society, May 17. D. BRunt: The adiabatic lapse-rate for dry and saturated air. The equation giving the saturated adiabatic lapse-rate is derived as an energy equation, and a slight approximation makes it possible to reduce this to a form suitable for direct computation. The results obtained are represented graphically. An alternative derivation of the fundamental equation for rising saturated air is given, which, by assuming the principle of entropy from the beginning, reduces the derivation to very brief compass. C. S. DURST : Notes on the variations in the structure of wind over different surfaces. Over the sea, the short-period fluctuations in wind are greater in tropical air than in polar air, although when inversions of any magnitude occur over the sea, smooth-flowing air can persist with higher velocities than over agricultural land. An example is shown of the structure of wind over desert, and the frictional churning of the air due to a town is examined; the effects on temperature are found to be appreciable. C. E. P. Brooks and THERESA M. HUNT : Variations of wind direction in the British Isles since 1341. Regular observations of wind direction began near London in 1667, at Edinburgh in 1731 and at Dublin in 1725, and extend, with gaps in the earlier periods, to the present day. Over nearly the whole series the prevailing wind has blown from about west-south-west, but abnormally frequent easterly winds were recorded during the period $1740-48$ in London and Dublin and during the period 1794-1810 in London. The present century has been remarkable for the persistence of south-westerly winds. Before 1667, observations are scanty but Merle's diary shows a dominant wind from west-south-west in the years 1341-43, while there is good evidence that easterly winds were abnormally frequent during the latter half of the sixteenth century.

\section{LEEDS}

Philosophical and Literary Society, March 3. R. WHIDdington and J. E. TAYLOR: Inelastic scattering of electrons in helium at zero angle. Experiments on electron impacts, energies between 40 and 400 volts, with helium atoms have been carried out, the inelastically scattered electrons at zero angle recejving special attention. It is shown that for the $2^{\prime} P$ excitation : the probability is very approximately a linear function of the energy of the incident electrons between about 40 and 400 volts energy; the pro. bability of excitation falls to zero at an energy somewhat greater than that corresponding to the critical excitation energy; and the excitation probability is definitely lower than that predicted by recent theories. R. Whiddrngton and T. Emmerson : Scattering of electrons in helium. The experimental and theoretical results so far published indicate that both the inelastic and elastic scattering of slow electrons in helium rise to a maximum for zero scattering angle. Using fine electron beams and narrow slits together with magnetic spectrum analysis and photographic recording, results have been obtained at smaller angles than those hitherto investigated, which show a maximum probability at a small angle with a low probability at zero angle. R. Whiddington and F. C. Poultney : Energy of the beams in electron diffraction. The experiment of G.P. Thomson on the velocities of electrons diffracted by passage through a thin film has been repeated. Greater resolving power is obtained by using $90^{\circ}$ deviation, when the circular rings become elliptical but are found to remain symmetrical about the central spot. Consequently it is deduced that the velocities are the same to within 0.30 per cent. No trace of diffracted electrons of energy less than that of the main beam is found. EDMUND C. STONER: Interatomic distances and ferromagnetism. Slater's suggestion as to the variation with interatomic distance of the sign and magnitude of the interaction integral is discussed with reference to the relative values of the interaction in the ferromagnetic elements, the change in volume on magnetisation, the variation of atomic moment in alloys of ferromagnetic elements, and the effect of manganese on the atomic moment in nickel manganese alloys. E. C. Pollard : Law of force between neutron and proton. The increase of the heights of nuclear potential barriers with the increase in atomic number is discussed from the point of view of the content of the nucleus; if a polarisation field is assumed between neutron and proton, the experimental figures permit the calculation of the 'polarisibility' of the neutron. This is done. A. W. Foster : Some measurements of the thermoelectric powers of nickel and nickel-chromium alloys in the neighbourhood of their Curie points. The thermoelectric powers of some nickel-chromium alloys have been accurately measured between $100^{\circ} \mathrm{C}$. and $450^{\circ} \mathrm{C}$. and the destructive effect of small amounts of chromium on the change at the Curie point in nickel confirmed. J. Grainger and Rachel M. Heafford: Some effects of the ordinary tobacco mosaic upon the developmental anatomy of the host plant. Many virus diseases cause a mottling of yellow and dark green areas to appear upon a leaf. The anatomy of these several areas has been studied by many workers who have examined cross sections of the leaf. A recent paper by the authors (Proc. Leeds Phil. Soc., 2, No. 9, 1933), describes the anatomy as revealed by examination in planes parallel to the surface, and also shows the various stages of development of mosaic diseased and healthy leaves. The presence of the virus has the general effect of slowing down the rate of vacuolation of leaf tissues, but it also causes irregularities to appear. The hypothesis is advanced that the anatomical features associated with light green and dark green areas of a diseased leaf can be explained by different relative rates of vacuolation in the upper epidermis, the palisade, the spongy parenchyma and the lower epidermis. 


\section{PARIS}

Academy of Sciences, April 18 (C.R., 196, 1153-1176). M. Granoux and L. Moret : The prolongation in Haute-Savoie and in Switzerland of the structural units of the Dauphiny Alps. D. van Dantzig: The fundamental group of compact abstract groups. SAINTILLAN : Forces of inertia of a system and a carrying along movement. R. Tremblot: A variable star with eclipses of short period. The star BD. $10 \cdot 838$ (Henry Draper Catalogue, H.D. 26909) has been recently shown by $\mathrm{C}$. Hoffmeister to be a variable with very short period. The author's observations from January until March, 1933, confirm this and suggest that the variability is due to two stars and not to one star rotating on itself. Mme. RÉchID : Study of the thermal decomposition of ammonium phosphate. Mrises. M. Montagne and G. Rousseau : The preparation of the anils of fatty ketones. Henri Lagatu and Louis Maume: The comparative composition, in the vine, of homologous leaves taken respectively from stems carrying fruit and stems deprived of their grapes. The leaves from stems carrying grapes are poorer in lime, nitrogen and potash but richer in phosphoric acid than the homologous leaves from sterile branches. A. Magnan and A. SAINTE-LAguË: Analysis of the 'hovering' of the Volucella. E. Fourneau, M. and Mme. J. Trefouk̈l, D. Bovet and Pierre Ketschet : Chemicotherapy of infections with Trypanosoma congolense. The selective action of polyarsenical organic compounds.

\section{Cracow}

Polish Academy of Science and Letters, Jan. 9. L. Chwistek, W. Hetper and J. Herzberg: (1) The fundamentals of rational metamathematics. Remarks on the fundamentals of rational metamathematics. M. Jezewski and J. Kamecki : The dielectric constants of aqueous electrolytes. The dielectric constants of solutions of various electrolytes have been measured at concentrations varying from zero to $0.01 \mathrm{~N}$. K. Dziewoński and L. Sternbach : The reactions of $\alpha$-naphthylamine with benzoyl chloride. MLLe. J. AckermanN : The innervation of the skin of Amblystoma mexicanum. Z. KoloDZIEJSKI: The transplantation of young larvæ of axolotl on adult animals. L. W. WISNIEWSKI : Remarks on the systematics of the family of Coitocæcidæ. T. Vetulani : Researches on the types of Arab horses raised in Turkey.

\section{Geneva}

Society of Physics and Natural History, Feb. 16. F. CHODAT and M. JunQUERA: The reduction of methylene blue by an Endomyces at the expense of its endocellular hydrogen donators. The authors study the variations of the reducing activity of Endomyces Chodati in the system : methylene blue (acceptor), living yeast (ferment), in the absence of an extra-cellular hydrogen donator (Thunberg's technique, MacIlvaine's buffer mixture, temperature, $40^{\circ}$ C.). The optimum conditions of $p \mathrm{H}$, and of the age of the organisms are described. $\alpha$-Monobromacetic acid, even when added in high conceritrations, is without effect on the enzymatic process. M. GYsIN : Petrographic researches in the Haut-Katanga. (2) The formations of the Kundelungu. In the south-east part of the Haut-Katanga, the Kundelungu is represented from bottom to top by a schisto-grit dolomitic and clay conglomerate (tillite), by limestones and dolomite massifs, dolomitic grits with a little felspar and clay, by lustrous schists sometimes containing grit and by felspathic and dolomitic grits passing to quartzites. The author gives the correlations between these formations and those recognised in northern Rhodesia and in the cupriferous district of the Katanga. He then describes the petrographic constitution of these different rocks. A. LombarD : The Virgulian and the stratigraphy of the Portlandian of the Col du Marehairuz region. The Virgulian in the neighbourhood of the Col du Marchairuz and the Monts de Bière (Vaudois Jura) has been described by various geologists. Completing these data, the author demonstrates that this sub-stage is reduced to zero to the south-west of the Marchairuz. It is then impossible to distinguish the lower Portlandian from the upper Kimmeridgian. The upper Portlandian is characterised by marly limestones, important dolomitic levels and cargneules. The latter increase in thickness from north-east to south-west. The dolomitic layers diminish. H. Palllard and $R$. DUCKERT : Researches on the catalytic oxidation of acenaphthene. The authors have studied the oxidation of acenaphthene in solution in various solvents by the action of compressed oxygen and in the presence of catalysts capable of giving oxides of nitrogen. Under these conditions the only important oxidation product is naphthalic acid. H. PALLLARD and P. Favarger. Researches on the chlorination of acenaphthene. The authors have studied the action of chlorine on acenaphthene and the conditions necessary for obtaining a good yield of 5-chloroacenaphthene. A. Perier: The influence, in a homogeneous ethnic group, of the variation of the cephalic index on that of the alveolo-palatinal and superior facial indices. The superior facial and alveolo-palatal indices show no correlation with variation of the cephalic index. Hence their relative stability, a disharmony inasmuch as the most brachycephalic skulls, are, proportionally, the most leptene and the most leptostaphyline. G. TIERCY : The respective phases of minimum ionisation and light minimum in the Cepheids. The author attempts to show how the combined effect of the curve of radiul velocities, of that of light and of the theory of radiating equilibrium affords an explanation of the fact that the minimum ionisation phase precedes the light minimum.

\section{Forthcoming Events}

[Meetings marked with an asterisk are open to the public.]

\section{Wednesday, June 7}

Fork-Lore Sociery, at 8-(at University College, Gower Street, W.C.1).-Mrs. E. S. Drower: "Mandean Magic, White and Black". (Discussion).

\section{Thursday, June 8}

London Schoor of Hygrene and Tropical Medicrne, at 2.-Sir George Buchanan : "International Hygiene" (succeeding lecture on June 9).*

University College, London, at 2.30.-Sir Flinders Petrie : "Egyptian Links with the Past" (to be repeated on June 10 at 3 , and June 13 at 5.30).*

Royal College of Physicians of London--(Croonian Lectures).--Prof. E. Mellanby : "Nutrition and Disease - the Interaction of Clinical and Experimental In. vestigations" (succeeding lectures on June 13 and 15). 